\title{
An Innovative Vessel for Research Studies at Amazon as a Potential Support for Sustainable Development and Conservation of the Region
}

\author{
Luís Otávio Vieira Meliande ${ }^{1 *}$, Afrânio de Amorim Francisco Soares Filho $^{2}$, Marcus \\ Vinícius de Araújo Fonseca ${ }^{1}$ and Fernando Pellon de Miranda ${ }^{3}$ \\ ${ }^{1}$ Programa de Engenharia de Produção/COPPE; Universidade Federal do Rio de Janeiro; Rio de Janeiro - RJ - \\ Brasil. ${ }^{2}$ Departamento de Administração; Faculdade de Estudos Sociais; Universidade Federal do Amazonas; \\ Manaus - AM - Brasil. ${ }^{3}$ Centro de Pesquisas e Desenvolvimento Leopoldo Américo Miguez de Mello; \\ Petrobras/CENPES; Rio de Janeiro - RJ - Brasil.
}

\begin{abstract}
This study proposes an innovative and demonstrably necessary vessel intended for the research and logistic support of scientific or non-scientific activities in the Amazon, designed in accordance with the environmental and geographical requirements and characteristics of the region (possibly applicable to other similar hydrographic basins). The study also demonstrates the existence of a demand (actual and potential) for the infrastructure proposed. This infrastructure could subsidize the efforts devoted to the expansion of knowledge about the region, since many areas of science, institutions and business segments could benefit from its implementation. The access to knowledge could attract private investments with the perspective of developing business whose origin has been a rational and sustainable exploitation of the natural potential of the region.
\end{abstract}

Key words: Research vessel, research boat, Amazon, sustainable development, conservation

\section{INTRODUCTION}

This study is essentially based on the urgent need to adopt a new development paradigm for the Amazon region, which is home to the largest hydrographic basin on the Planet, the Amazon Basin, which occupies 6,112,000 $\mathrm{km}^{2}$ area (Salati et al. 1998), 58\% of which is in the Brazilian territory (Lima et al. 1998). It is imperative to implement measures to reduce and, subsequently, cease the predation of natural resources in the region. The model to be adopted should prove relevant and socially sustainable in any viewpoint or future scenario. The alternative outlined here aims to propose an innovative and necessary infrastructure destined to the research and logistical support of scientific or non-scientific activities in the Amazon (applicable to other similar hydrographic basins). Structured from a research vessel designed in accordance with local environmental characteristics and identified demands, it would be built and managed by LabAmazon Pesquisa e Desenvolvimento Ltda. This company is an academic spin-off, derived from the academic research project developed at the Alberto Luiz Coimbra Institute of Postgraduate Studies and Research in Engineering (Coppe) of the Federal University of Rio de Janeiro (UFRJ). This study, also referred as Project, Laboratory and LabAmazon - is to present the general characteristics of the naval infrastructure, as well as a survey of the demands, existent and potential, which could benefit and endure this Floating

*Author for correspondence: meliande@ig.com.br 
Research Station (Fig. 1), whose structure would bear a fully equipped laboratory, destined to the development of multidisciplinary basic and applied research, adapted to the needs and conditions of the Amazon region. Non-scientific activities supported by LabAmazon include ecotourism and biotic and abiotic sample collection, among others. The study intends to introduce to academia, government, business community and society as a whole an innovative and multifunctional way of accessing knowledge in the Amazon region, which could attract investments with the perspective of developing sustainable enterprises.

\section{MATERIALS AND METHODS}

The physical model presented here is the result of the academic work Floating laboratory for the Amazon: proposal of a scientific research infrastructure model for the Amazon Region (Meliande 2001), developed with the support and participation of several organizations that could potentially benefit from the implementation of this study. The results were adapted with the support of the naval engineers Antônio Pedro Tonon and Claudio da Silva Tarrisse Fontoura, the latter being designated by the Engineering Directorate of the Brazilian Navy in support of the academic proposal and responsible for the preparation of the Project Requirements, as well as for the floor plant that gave rise to the model presented here. The propositions about the requirements of the potential users were surveyed by the means of a roundtable and questionnaires, besides other materials included in the cited study. A comparative analysis with the boat-lab Amanaí II (Fig. 2), belonging to the National Institute for Amazonian Research (INPA), was also carried out. This vessel was the only existing infrastructure in the country that combined characteristics that were related to the study, being therefore considered for comparison purposes since it was the most similar to the subject of this proposal. Aiming to demonstrate the feasibility and necessity of seeking the prompt achievement of the project, the potential demand for the proposed infrastructure was identified from two separate surveys: one academic, the other marketing. The first intended to identify the universe composed of potential beneficiaries of the infrastructure that originated from the national academia. For this, the electronic databases of the
National Council for Scientific and Technological Development $(\mathrm{CNPq})$ and of the Coordination for the Improvement of Higher Education Personnel (Capes) were consulted. The available data referred to the years 2010 (Capes) and 2011 $(\mathrm{CNPq})$ and demonstrated how many scholarships were granted by both the institutions to researchers with projects related to the Amazon.

The second survey, whose results would be summarized, occurred through an assessment of the marketing universe, that is, institutions that expressed interest and/or possibility to rent a research infrastructure such as the one offered by the research vessel proposed here. The results, generated in the form of a Technical Report entitled Survey: LabAmazon marketing viability, was prepared by two of the co-authors of this paper, Meliande and Soares Filho, and performed especially for LabAmazon by the company, Action Pesquisas de Mercado Ltda., located in the city of Manaus, Amazonas (AM), with non-reimbursable funds approved by the Studies and Projects Finance Organization (Finep), through the announcement of the First Innovative Business Program (Prime), in 2009.

The data assessment was developed by the means of a survey method (Malhotra 2006), using nonprobability sampling applied to small populations (Hansen et al. 1953; Kish 1965; Bolfarine and Bussab 2005; Hill and Hill 2008). The research universe was restricted to the experimental exploratory research institutions only, with headquarters or subsidiaries operating in the country. The desired filter certainly reduced the amplitude of the universe to a small and select group of organizations (Cochran 1977; Hill and Hill 2008). To identify those with the desired profile, a list of organizations with an inclination to the research interest was used as a reference (Meliande 2001). Secondary data obtained with the Ministry of Science and Technology by the Action and through the opinions of experts and teachers, drawn from in-depth interviews conducted individually and in groups (Minayo et al. 2001), were also employed. From this scope, a list of 74 institutions was drawn up - from private companies, governmental and non-governmental agencies -, all situated predominantly in the North region and in the states of Rio de Janeiro, São Paulo and the Federal District. During the planning of data collection, the primary intention of the authors was, due to the reduced size of the universe to be researched, to conduct a census 
approach (Särndal et al. 1992); however, part of that target audience proved resistant or uninterested in participating in the study, leading to the choice of a non-probabilistic sampling approach, stratified by the quotas, according to the type of organization studied (Malhotra 2006).

The sample was calculated, at first, meeting the guidelines of Hill and Hill (2008), whose indication was the "Rule of Thumb". It was based on the minimum size required for the application of normality tests and sample consistency. Such a method, suitable for small research universes, estimated that the size of a sample should not be less than 30 individuals. The objective of sampling in the research work field was to estimate the proportion of use of vessels for the purposes of logistics and scientific research. To do so, the recommendations of Hill and Hill (2008) were followed, with a confidence level of 95\% ( $\mathrm{Z}=$ 1.96), proportion of use $\mathrm{P}=50 \%$ and Square Critical difference $\left(\mathrm{D}^{2}\right)=0.05 \%$.

As shown in Eq. (1), the size of the sample (n) was $45(\mathrm{n}=45)$, within a finite universe of 74 organizations. To obtain this result with a confidence level (95\%), the sampling error was \pm $9.19 \%$.

$$
n=\left(P(1-P) Z^{2}\right) / D^{2}
$$

The standard error is most often used in probabilistic sampling for building confidence intervals that will contain the true value of the population proportion $(\mathrm{P})$, with a certain probability due to the desired level of confidence to the decision-making. As it was a small universe and the primary interest was to get a census survey, a correction factor was used to estimate the standard error for small samples, considering the proximity of the sample size to the total number of individuals within the universe.

In practice, a confidence interval of $95 \%$ indicates that in each 100 samples selected using the same method, 95 will produce $\mathrm{P}$ estimates, whose confidence interval will contain the true value of the population proportion; and, in 5 samples the estimated value could be outside that range. Naturally, the higher the level of confidence required, the greater the amplitude of the confidence interval - and the decision on this level is based on the degree of accuracy that the customer needs in the analytical work. Thus, the size of the sample is irrelevant because it is a significant percentage of the total population under study. In this case, the size is not important, as Lewis (2001) contends.

\section{Data Collection, Processing and Analysis}

The process of data collection was developed by individual interviews conducted by the researchers that were especially qualified for the study, with the application of a structured questionnaire formed mostly of single and multiple choice closed- and open-ended scaled questions. The interviews were carried out directly with key informants over telephone (Malhotra 2006). The process of obtaining the data, the qualified individual interview, was applied personally with a guarantee of confidentiality, with the agent responsible for making decisions on the use of the proposed infrastructure. The period of data collection occurred from May 26 to July 16, 2010. For this purpose, a questionnaire composed of 61 questions was used.

The collected data were processed by the means of descriptive statistics, normality tests and multiple linear regression analysis (Hair Jr et al. 2010). For the numeric variables, by way of comparison, the simple average for each indicator was used as a parameter analysis. The open-ended questions of the questionnaire were transcribed verbatim as told by its respondents. These text-generated records were treated by the means of content analysis (Malhotra 2006) and, for the scales, the Cronbach's Alpha Coefficient was used as an internal consistency test.

\section{RESULTS}

\section{The Vessel Model Proposed}

The studies that led to the physical model proposed herein had their results presented in the form of a Masters dissertation (Meliande 2001). The model (Fig. 1 and Figs. 3-6) showed the aggregated suggestions and criticisms expressed by the means of an extensive research with the universe of potential users of the vessel, and represented an important alternative to supply the demand for a better research infrastructure for the Amazon. Thus, it allowed interdisciplinary scientific practice and was able to meet simultaneously the needs of multiple areas of science. Its main objectives were:

1. Build a modern and versatile floating research station for the Amazon, capable of meeting scientific and entrepreneurial demands, 
providing environmental services and contributing to the sustainable development of the region;

2. Collect, prepare and stow samples and data, of any kind, originated from the Amazon;

3. Provide the necessary infrastructure for the installation and operation of in situ analysis equipment;

4. Enable the joint and multidisciplinary work of researchers in expeditions;

5. Enable the first series of large scientific expeditions through the Amazon of the twentyfirst century;

6. Expand, in a significant manner, the databases available today on the Amazon and better understand its role as regulator of the global climate.

The development process of the physical model also undertook a comparative analysis with the boat-lab Amanaí II. Its characteristics were confronted with the propositions collated for the project, which generated innovations and provided the basis for the configuration of the final model proposed. When comparing the present proposal with the boat Amanaí II, the latter turned out to be a very limited facility. However, it was noteworthy that several innovations proposed for LabAmazon had origin or inspiration on the very object of the comparative study. Therefore, it was worth not only recognizing the value of that pioneering work, but also emphasizing that part of what could be considered "positive" or "innovative points" of the Project proposed here came from the knowledge gained from a previous experiment.

When proposing a scientific facility that offers greater interior space, comfort, security and better working conditions for its users, it is sought to overcome, when applicable, the positive features of the current state of the art. Thus, Amanaí II functioned as an extremely useful reference, providing important information to support the structuring of this study. With the comparative analysis, it was possible to refine the points considered positive (e.g., two generators for emergency situations), aggregate facilities hitherto non-existent (e.g., infirmary, helipad etc.) and, at the same time, avoid the aspects pointed out as being negative (e.g., the Amanaí has only one engine; the propellers were exposed below the hull). Table 1 summarizes, the features present in the Amanaí II and in the LabAmazon, mentioning all the facilities proposed in this study for subsequent comparison with those existing in Amanaí II - whose data were obtained with INPA, followed by the relevant comments.

Table 1 - Comparison of the facilities planned in LabAmazon with those of Amanaí II.

\begin{tabular}{lll}
\hline Facilities of each vessel & LabAmazon & Amanaí II \\
\hline Research Lab & 2 & 1 \\
Computer Lab & 1 & Non-existent \\
Number of Researchers & 22 (in double cabins, with bathroom) & 17 (double or quadruple cabins) \\
Number of Crew Members & 6 & 5 \\
& Living room, bar, along with extensive free & \\
Leisure Areas & areas on the upper deck, at the stern and the & Only areas in the stern and the bow \\
bow & Non-existent \\
Lnfirmary & Planned & Non-existent \\
Halls & Planned & Smaller, because of its overall \\
Auditorium & Large, due to better use of space and the & dimensions (30 m X 7 m) \\
Air Conditioning & overall dimensions (33 $\mathrm{X}$ 11 m) & Non-existent \\
Research and & 1 (the cafeteria is converted into auditorium) & Individual devices (several areas \\
Communication Equipment & Central, in all areas & are not climatized) \\
Helipad & Modern and used for various applications & Limited and obsolete \\
Draft & Planned & Non-existent \\
Autonomy & Up until 1,10 m & $1,22 \mathrm{~m}$ \\
Service Speed & 2,000 nautical miles +20 days of & 1,500 nautical miles \\
Engines & unattended operation & 10 knots \\
Propellers & 12 knots & 1 engine of 378 hp \\
Energy Generation & 2 engines of about 550 hp each & Exposed below the hull \\
\hline & Embedded in the hull & 2 generators of 35 kva each \\
\hline
\end{tabular}




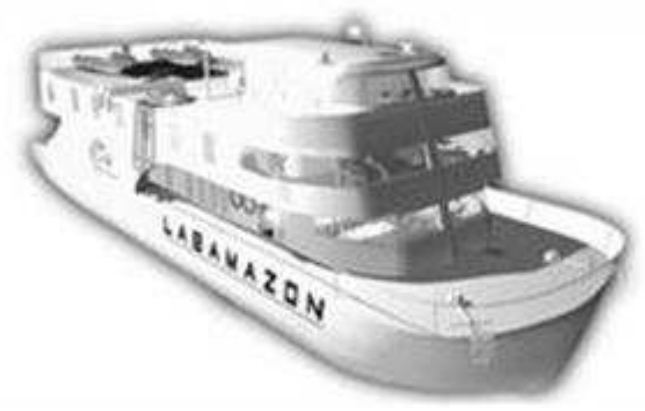

Figure 1 - Front view in perspective: at the top, the cockpit; below, on the deck, the living room; at the level of the bow deck, where the anchors are positioned, the cafeteria.

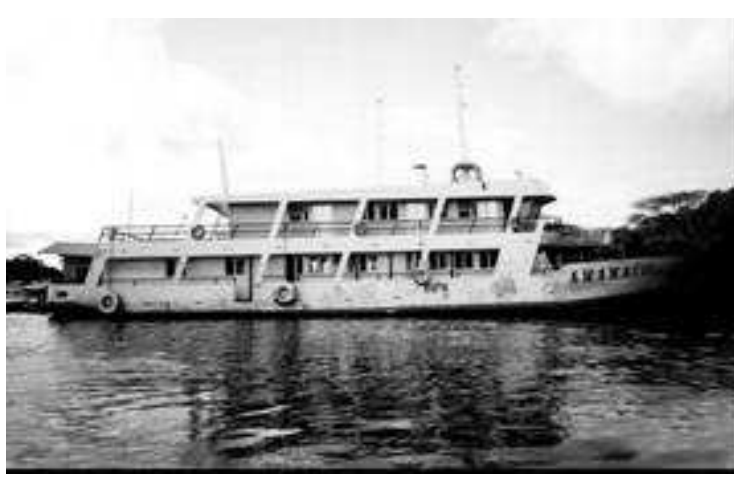

Figure 2 - Boat Amanaí II, docked at the INPA quay, in the banks of the Negro River, near the city of Manaus, AM.

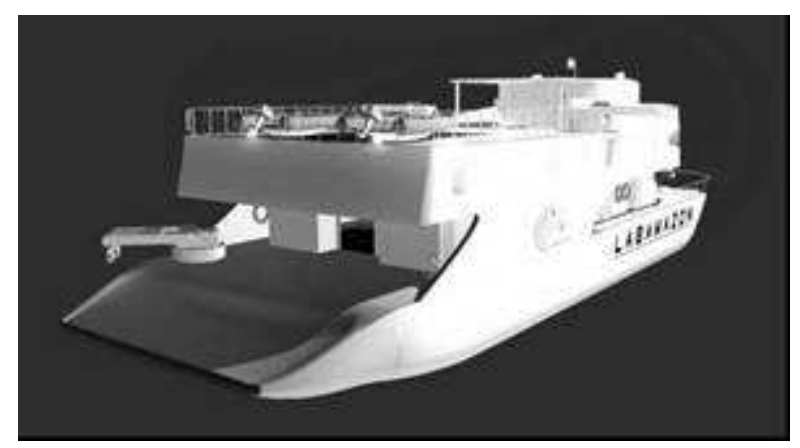

Figure 3 - Perspective view from the stern, where one of three hoists is seen, as well as the passage to the main lab. On the upper deck are two of the support boats.

As far as the investment was concerned, a ballpark figure was provided by Meliande (2013) in the order of US\$ 2,771 M (US\$ 2,156,000 for

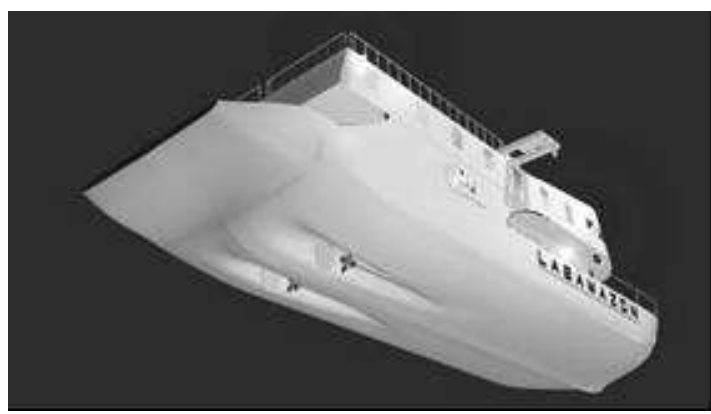

Figure 4 - Bottom view of the vessel's hull. In order to avoid compromising the proposed draft, the propellers will be embedded in two halfcones on the hull, thereby being also protected from submersed trunks.

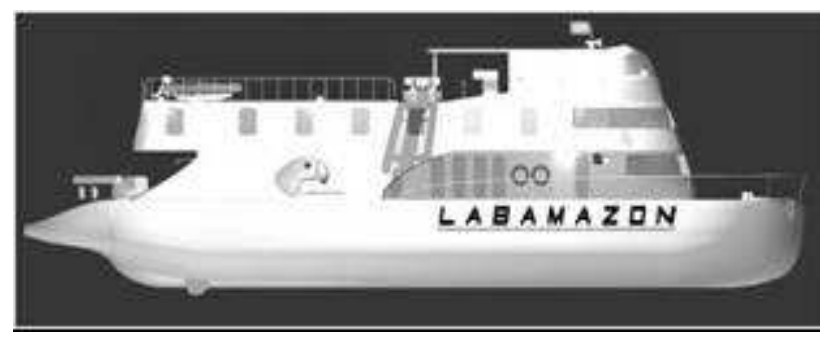

Figure 5 - Side view. Below the upper deck are the hatches of the cabins. On the main deck, above the word LabAmazon, is the side corridor that surrounds the vessel. On the side, the logo proposal for the project, reproducing the stylized head of a macaw.

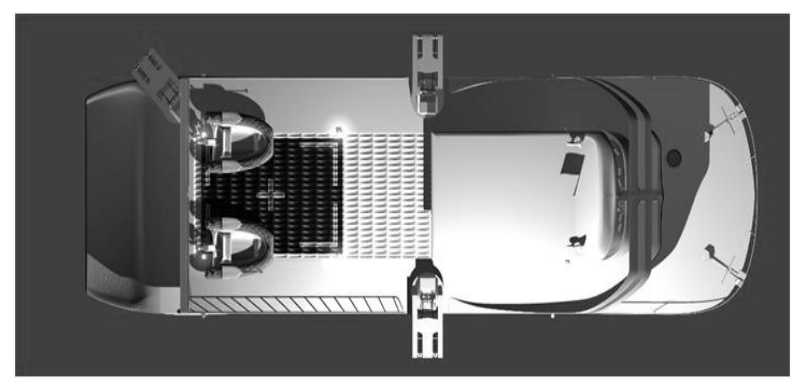

Figure 6 - Upper deck, with two auxiliary boats positioned on the helipad and two hoists on the sides, which are intended for loading equipment and various cargos, in addition to collecting sediment samples from the river beds. At the stern, two levels below, is a third hoist with lower load capacity.

construction and US\$ 615,000 for annual maintenance). However, such figures should be reevaluated considering, for instance, the exchange 
rate fluctuations, taxes and the price of the naval steel.

\section{Survey of the potential demand for use of the vessel}

Regarding the group composed of CNPq fellows, the survey considered only the recipients of scholarships that came from or were indicated by the institutions located in the states that formed the Brazilian Amazon, plus the federal capital, Brasília. The inclusion of those whose origin was the capital of the Country was due to the research studies carried out by the Brazilian Agricultural Research Corporation (Embrapa) that were financed by the Sector Funds of Science and Technology for the Amazon.

As the focus of the identification of this segment's demand was the estimation of the universe that consisted of academic users who could potentially benefit from the infrastructure of LabAmazon, scholarships destined to the areas of knowledge that, in theory, would not have a direct interest in the use the vessel were excluded. Thus, studies on, for example, the mathematics, dentistry, civil engineering, arts, management, etc. were not considered. The inventoried scholarships were only related to the areas that would potentially be beneficiaries of the services and facilities proposed, including, for example, studies related to biology, genetics, agronomy, zoology, chemistry, geosciences, geology, geography, ecology, botany, fishery resources, biotechnology, among others. The granted scholarships were from various $\mathrm{CNPq}$ institutional programs (e.g., Postgraduate Program, Basic Program of Parasitology, Basic Program of Environmental Science, etc.), Transversal Actions (strategic programs of the Ministry of Science and Technology) and from the Sector Funds focused on the segments of oil and natural gas, Amazon, shipbuilding and water transportation, water resources, biotechnology and energy. The quantitative data related to the number of scholarships supported by that Council covered a group composed of 2.238 beneficiaries.

From the Capes database, data referring to the year 2010 were collected, the last period made available by that institution. As technical limitations related to the access and tabulation of the data did not allow the reproduction of the same standards used in the study carried out at the CNPq database, the theses presented in 2010 by the fellows from the institutions located in the
Amazon component states were inventoried. Capes provided the file extracted from its Bank of Theses and Dissertations, entitled Legal Amazon. Theses and Dissertations - Year Base: 2010, in which the titles of 1.159 theses on the masters, professional masters and $\mathrm{PhD}$ levels were recorded, which all were presented in that year. Based on the premise that the research fellows who performed their related theses could potentially have benefited from the use of the infrastructure to be provided by the LabAmazon to perform their studies, theses were selected according to their respective titles. In determining the quantum of potential users among the 1.159 related theses, those whose studies suggested the topics and data collection in the field, or whose results could have taken the advantage of the structure mentioned, were selected.

\section{The potential academic demand}

Following the criteria described above, the survey conducted indicated that the total fellows supported by the CNPq in 2011, which could potentially benefit from the features offered by the project was 1.353 . The granted scholarships were divided into 12 different modalities as described in Table 2.

Table 2 - Fellows supported by CNPq that could be potentially beneficiaries of the LabAmazon infrastructure.

\begin{tabular}{lc}
\hline \multicolumn{1}{c}{ CNPq - Total fellows by modality in $\mathbf{2 0 1 1}$} \\
\hline Modality & Total fellows \\
Masters & 675 \\
Doctorate & 288 \\
Post Doctorate & 8 \\
Junior Post Doctorate & 19 \\
Senior Post Doctorate & 1 \\
Research Productivity & 244 \\
Technical Support & 19 \\
Research Support & 7 \\
Industrial and Technological & 9 \\
Initiation & \\
Industrial and Technological & 44 \\
Development & 2 \\
Visitor Specialist & 37 \\
Scientific Initiation & $\mathbf{1 . 3 5 3}$ \\
\hline Total fellows: & \\
\hline
\end{tabular}

With regard to the data provided by the Capes (2010), 645 theses were selected (i.e., fellows), representing $55.6 \%$ of the sample. Thus, it was estimated that if the vessel was available to the 
academic universe surveyed, a total of 1.998 fellows (1.353 CNPq +645 Capes fellows) could have benefited from the research infrastructure provided by the vessel in their studies.

Regarding the group focused by the study on the estimate of national academic demand, the exploratory character of this survey should be noted, which sought to indicate the existence of an academic sector that could potentially be beneficiary of the proposal. It could be stated with certainty that the expansion of the studied scope would indicate a higher number of potential users; i.e, if the study was not focused only on the fellows of the Legal Amazon, but throughout the whole academia universe, in Brazil and abroad, it would be conceivable to expect considerably larger numbers. Therefore, the estimated total of 1,998 research fellows could be greatly expanded. Future studies on the real dimension represented by this segment of demand could resize its specific stature, considering, for example, the academic non-fellow users, who were supported by the sources other than those surveyed (Capes and $\mathrm{CNPq}$ ), in addition to that generated by the researchers from foreign institutions.

\section{Marketing survey}

It should be noted that the amount and relevance of the data disclosed herein could be of great importance for the confirmation of the existence of a market for the services proposed. Besides the merits and the unpublished information on the present demand, it allowed for the prediction of the great potential that could be generated with the region's economic growth. In an unprecedented manner, the study not only identified the demand for a vessel equipped with a research infrastructure, but also pointed out the specific segments where they were from and their
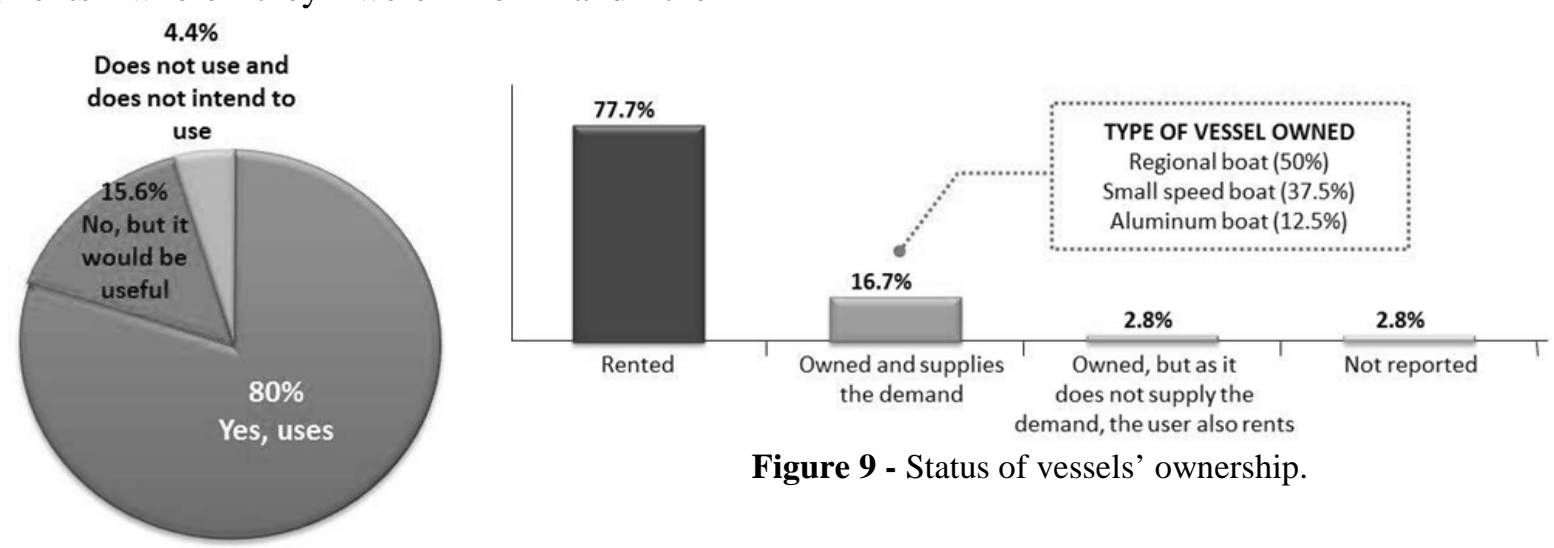

Figure 9 - Status of vessels' ownership. respective weights. Figure 7 shows the estimated group, divided by the segment.

On the portion of the sample that represented the users who could rent the vessels, the data collected by the study corroborated the thesis that there was already an actual demand for the infrastructure proposed by LabAmazon. It was observed that $80 \%$ of the organizations that participated in the survey (or 36 among 45 surveyed) used the vessels in their activities. Among the remainder, $15.6 \%$ (seven), although did not employ vessels, stated that they would be useful in their current or future actions. Only a small portion, representing $4.4 \%$ (two), did not use or plan to use this type of vessel (Fig. 8). However, in addition to measuring the group of the users who reported using vessels in their activities, the survey revealed that the vast majority $(77.7 \%)$ rented third party equipment (Fig. 9). Another $2.8 \%$ of the respondents had the vessels that did not meet their demands, being also forced to rent. Hence, $80.5 \%$ of the vessels used by the users were rented.

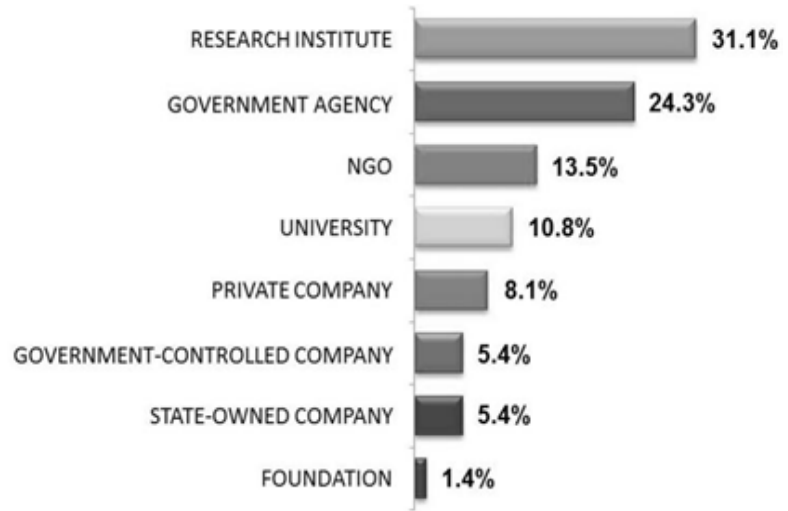

Figure 7 - Survey inventory by segment and their respective participation in percentage terms.

Figure 8 - Indication of interest in the use of vessels. 
The main reason expressed by the group of users was the great need of the vessel for scientific research activities (79.4\%). Its usage has been in different areas, such as environmental, geochemical, hydrological and biological. It could also be used for the logistical purposes, transporting equipment, personnel and cargo $(10.3 \%)$ and for environmental surveillance $(10.3 \%)$. It could additionally be useful as an instrument to support the management of conservation units, in technical training work, for data collection, as a platform for education and extension, among others. These data represented one of the strongest indications of opportunity already present in the market, which did not offer any vessel with features to support the scientific research such as the ones proposed by LabAmazon. Figure 10 presents the reasons mentioned for the use of vessels.

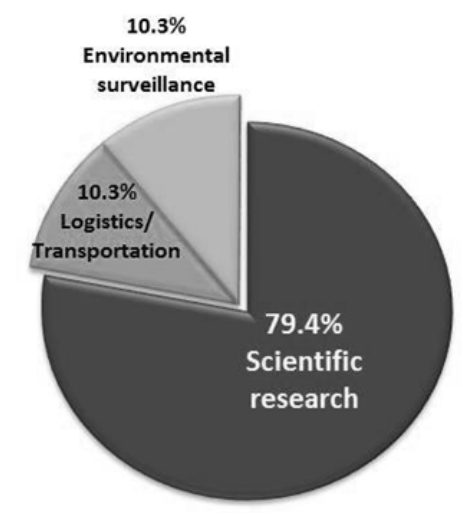

Figure 10 - Purpose of vessel use expressed by application segment
Considering the number of occasions that users rented the vessels, an average of 7.6 uses was obtained; but, for $10.3 \%$ of the sample, the volume was higher because they rented it 21 or more times (Fig. 11). On average, each of the field trips demanded the rent of vessels for 14.1 days. However, the highest concentration in the sample, equivalent to $34.6 \%$ of the users, made use of the vessels for up to 10 days. The amount spent on the vessels' rent was divided into daily rates and included crew, food and fuel. All values were updated by the General Price Index (IGP-M), adjusted to present value considering the date of July 31,2013 , no interest, and then converted to U.S. dollars at an exchange rate of US\$ 1 equivalent to $R \$ 2,30$. The average amount paid for the daily rate was US\$ 658. The majority $(27.6 \%)$, however, paid a daily rate of US\$ 264. The amount varied according to the infrastructure provided by the rented vessel. These data are shown in Figures 11, 12 and 13.

One of the most revealing data brought to light by the marketing feasibility study concerned the estimated size of the current market of rental vessels. Considering only the sample used in the survey, that is, 36 among the 45 companies interviewed with the profile of potential users, the study estimated that the current market operated by them was around US $\$ 2,540$ million a year. If these data (among the users and potential users) were extrapolated to the estimated universe of 74 companies, it could be concluded that the potential market for the rental of vessels with the proposed purpose was higher than US $\$ 5,217$ million a year in updated values. Figure 14 summarizes the values considered.

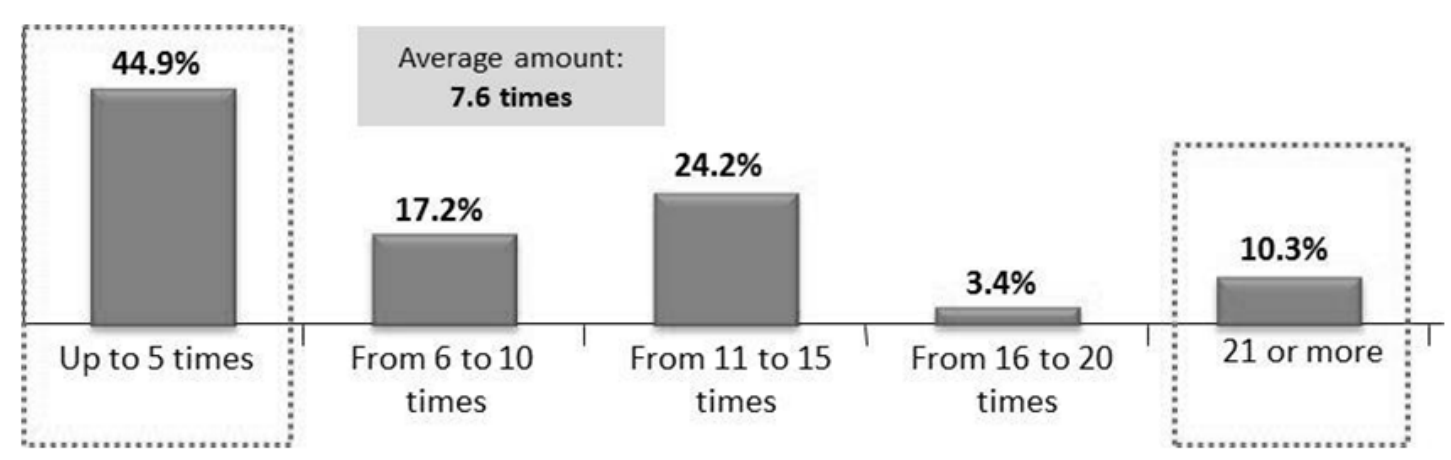

Figure 11 - Number of times per year that the vessels are rented. 


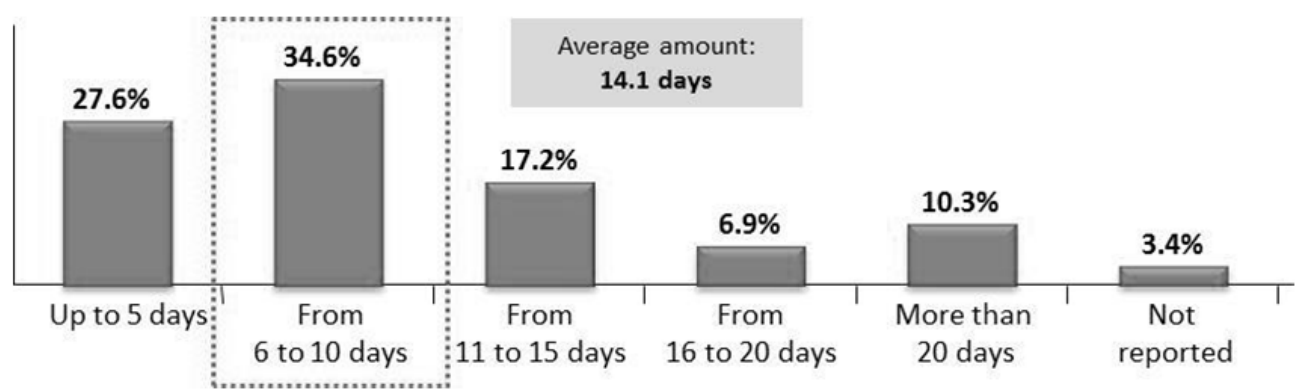

Figure 12 - Number of days used for each rental period.

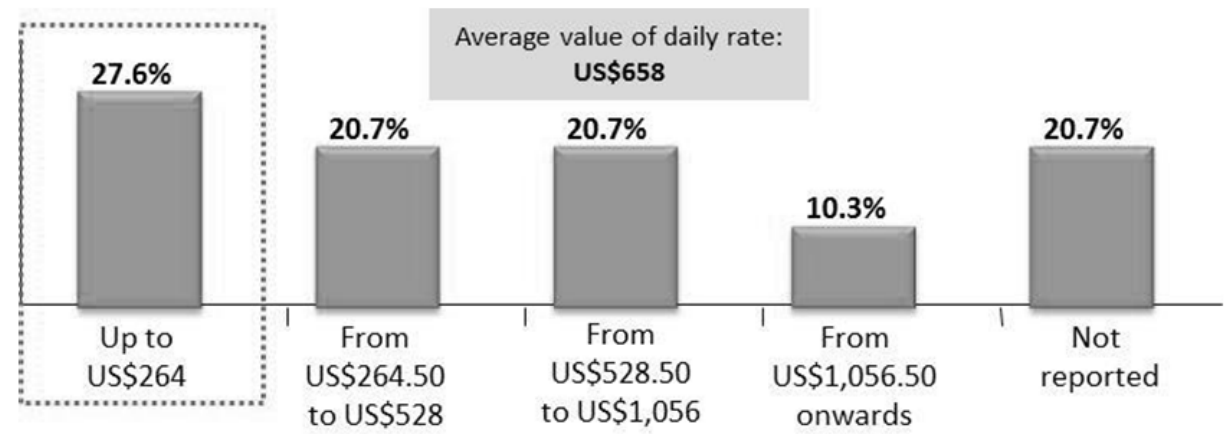

Figure 13 - Cost of daily rates.

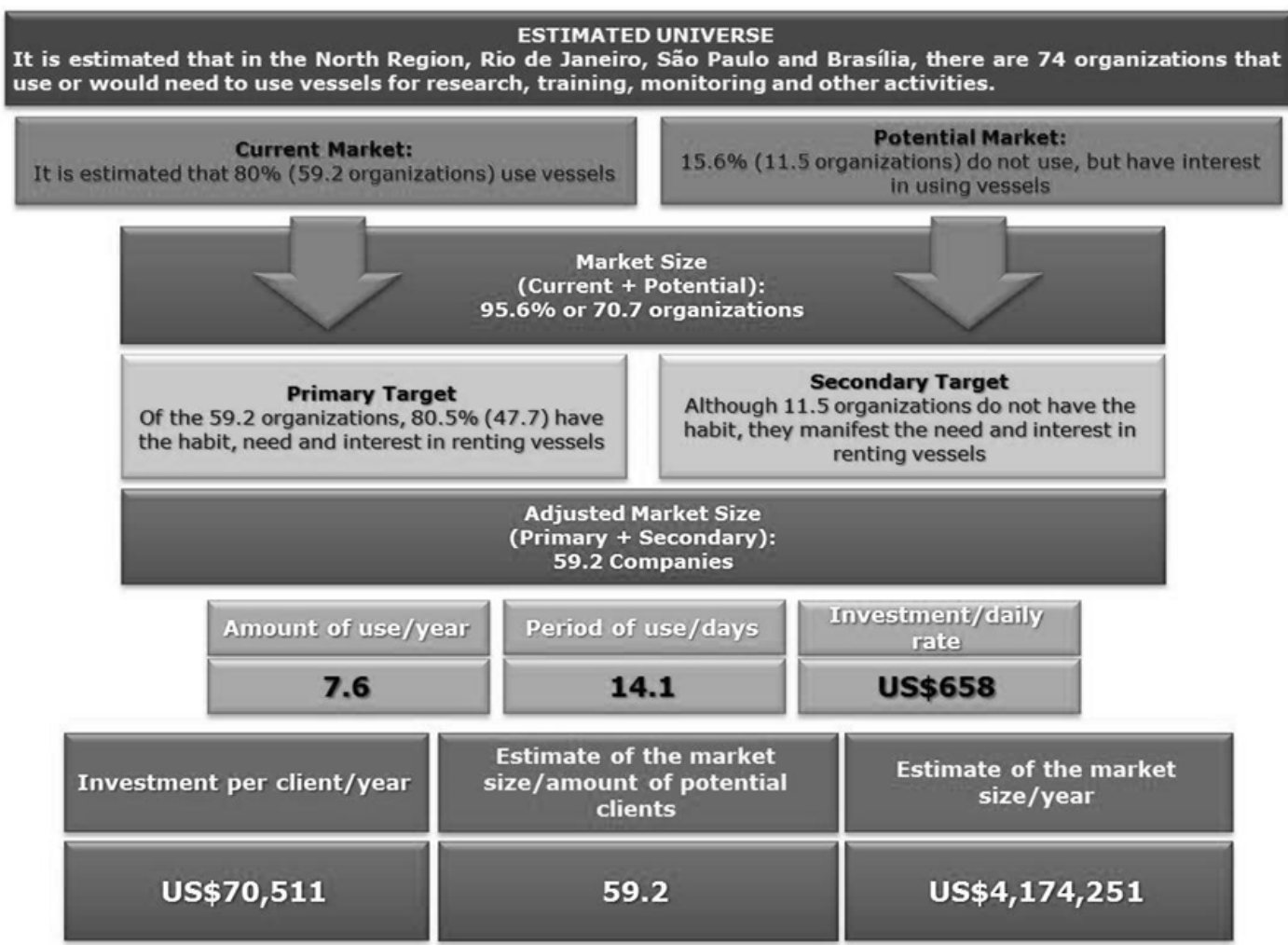

Figure 14 - Estimate, in values, of the size of the annual market for the rent of specialized vessels. 
Finally, considering the numerous criticisms pointed out by the users regarding the equipment available today (e.g., discomfort, lack of security and training of the crew, inadequacy to legal standards, precariousness or inadequacy of equipment), the supply of the vessels with characteristics that met the customers' requirements could meet a demand that was currently repressed, whose size was yet to be estimated.

\section{DISCUSSION}

The data obtained in the demand-related surveys reinforced the thesis that the services offered community a need that was already present, contributing to the identification of the group of the customers to be reached by the business model to be adopted. Whether actual or potential, such outline would be crucial in setting up a business model that could be capable of facilitating and sustaining its development. The knowledge of the universe in which it was inserted (even though it represented a portion of the demand) brought the response to the hypothesis formulated when filing a new business: for whom the service or product would be offered, i.e., who would be its customer. This information allowed for the model to be designed based on the assumption of the existence of a clientele that was able to generate revenue to the business in a sustainable manner.

Considering the data mentioned, it could be inferred that the demand for the infrastructure and the services offered justified the feasibility of the proposal. In addition to meeting the current and future demand for qualified services to support the economic activities already underway, the model showed it was also able to support the efforts related to the sustainable development of the Amazon from multiple segments. Brazil did not has a model based on an infrastructure that was nearly similar to the one proposed in this paper. Nevertheless, the exploitation of the region's natural resources could not proceed without a tool like this available. As an example, one can take the hydroelectric power plants (HPP) planned for the Amazon region by the year 2019, which will be added to the 17 already in operation. Even if the impacts caused by each individual generating plant and by the transmission lines used for transporting the energy produced are small, the set of HPPs will generate a considerable impact on the
Amazon biome. Thus, in the search for the "adoption of criteria and procedures for reconciling the use of energy sources and the conservation of biodiversity" (Brazil 2010), one must rely on an infrastructure that is capable of supporting the numerous studies demanded by such activities, now unavailable. As the projected draft of the vessel was $1.1 \mathrm{~m}$ (Meliande 2001), it would allow LabAmazon to navigate at river depths inaccessible to most of the existing facilities in the region, and also amplified its capillarity through the tributaries, even during the dry season.

Given the grandeur and importance of the region to Brazil and the rest of the planet, this process should also consider other components that, evaluated as a whole, would allow for the measurement of the urgency of adopting a development model that would be truly sustainable, capable of generating wealth from the rational use of its natural resources.

Future studies should take into account other issues that directly or indirectly relate to the present proposal, such as technological innovation and its main source, research and development (R\&D) - considering the origin and focus of the enterprise for which the model is proposed. Another object of analysis should be the funding mechanisms such as the venture capital or risk capital, which could be used as investment tools for the feasibility of the proposal. There is a possibility of conducting surveys on the potential demand for the vessel's use, made in order to scrutinize the potential related to other market segments or the international academic demand. And, finally, the legal and institutional aspects of the proposal must be considered in the light of this study's proposition, since its implementation meets public policies focused on the Amazon and on the development of innovative companies.

\section{CONCLUSIONS}

Preserving the Amazon requires the adoption of a development model that is capable of promoting the sustainable exploitation of its natural resources. Both, preservation and development require an extension of the knowledge about the area. Given its environmental characteristics, the production and access to knowledge require specific means, being a research vessel an extremely important infrastructure in this process. 
Through the proposed model, a correct and useful access of, for example, its immense genetic heritage would be possible. However, many areas of science, institutions and business segments would be benefited from its implementation. Activities related to the collection of environmental data, material, transportation of researchers, studies of social and environmental impact assessment, logistical support, etc could be examples of the actions to be performed by the use of the vessel. The access to knowledge could attract private investments with the perspective of developing business whose origin might be a rational and sustainable exploitation of the natural potential of the region. This measure could, for example, contribute for the Amazon to become a biotech hub of worldwide projection, generating wealth from its immense and unique genetic heritage.

The study also demonstrated the existence of a demand (actual and potential) for the infrastructure proposed. Meliande (2001; 2013) provided information obtained from a general survey carried out with potential users (including governmental agencies, academia, NGOs, and industry). Although, per se, the data collected justified the prompt achievement of the study, future studies should dimension and identify the universe comprised of all the potential users, including from abroad.

The presentation of this model could be a milestone in the long quest for the accomplishment of an innovative project linked to a demand for the services offered, and could bring significant benefits to the adoption of a new and necessary development model for the Amazon. It might function as the antithesis of those models that throughout history were based on the unsustainable exploitation of natural resources of the region, degrading the environment and local societies, and creating a permanent loss of irreplaceable inputs and knowledge of great value to Mankind. With the need, usefulness and demand for this infrastructure reported here, the achievement of this goal should be listed alongside other priority structuring initiatives proposed to the Amazon. The feasibility of this study could lead to the expansion of the horizons of human knowledge, franchising one of the most important and powerful tools used to face multiple challenge. It could worthy to note that important Brazilian entities, such as UFRJ/Coppe and Finep, have already expressed their official interest to institutionally support LabAmazon (Meliande 2001; 2013).

\section{ACKNOWLEDGMENTS}

The author thanks to the UFRJ/Coppe for the institutional support during the development of master's and doctoral degrees. Capes, $\mathrm{CNPq}$ and Petrobras/Cenpes provided financial support in the form of scholarships. Finep granted support to LabAmazon through the First Innovative Company Program; the Brazilian Navy offered technical inputs. The naval engineers Antônio Pedro Tonon and Claudio da Silva Tarrisse Fontoura personally engaged in the success of the proposal presented here.

\section{REFERENCES}

Bolfarine H, Bussab WO. Elementos de amostragem. São Paulo: Ed. Blücher; 2005.

Brasil. Ministério de Minas e Energia (BR). Plano Decenal de Expansão de Energia 2019. Brasília: Empresa de Pesquisa Energética; 2010.

Brasil. Ministério do Desenvolvimento, Indústria e Comércio. Plano Brasil Maior: 2011-2014. Disponível em: <www.mdic.gov.br/brasilmaior>. Acesso em: 12 abr. 2012.

Cochran W. Sampling techniques. 3rd ed. New York: Wiley; 1977.

Conselho Nacional de Desenvolvimento Científico e Tecnológico. Base de Dados CNPq. Assessoria de Estatística e Informação. [homepage on the internet]. [cited 2013 June 10]. Available from: <www.cnpq.br>.

Coordenação de Aperfeiçoamento de Pessoal de Nível Superior. Banco de Teses e Dissertações. Ano base: 2010.

Hair Jr JF, Wolfinanbarger M, Ortinau D, Bush RP. Fundamentos de pesquisa de marketing. Porto Alegre: Bookman; 2010.

Hansen MH, Hurwitz WN, Madow WG. Sample survey methods and theory. New York: Wiley; 1953.

Hill MM, Hill A. Investigações por questionário. Lisboa: Sílabo; 2008.

Instituto Brasileiro de Geografia e Estatística. Indicadores de desenvolvimento sustentável: Brasil 2012. Rio de Janeiro; 2012.

Instituto Nacional de Pesquisas da Amazônia [homepage on the internet]. Manaus: Inpa; [cited 2013 June 10]. Available from: http://www.inpa.gov.br/.

Kish L. Survey sampling. New York: Wiley; 1965. 
Lewis JR. Sample Size Estimation and Use of Substitute Audiences. Speech Product Design and Usability. West Palm Beach, FL; 2001.

Malhotra NK. Pesquisa de marketing: uma orientação aplicada. $4^{\text {th }}$ ed. Porto Alegre: Bookman; 2006.

Meliande LOV. Floating Laboratory for the Amazon: proposal of a Research Infrastructure Model for the Amazon Region. [Master's Thesis]. Rio de Janeiro, Brasil: Universidade Federal do Rio de Janeiro; 2001.

Meliande LOV. Labamazon: Structure of an Innovative Business Model for the Promotion of Scientific and Technological Activities in the Amazon. [PhD Dissertation]. Rio de Janeiro, Brasil: Universidade Federal do Rio de Janeiro; 2013.
Minayo MC, Deslandes SF, Cruz Neto O, Gomes R. Teoria, método e criatividade. Petrópolis: Vozes; 2001.

Salati E, Santos AA, Lovejoy TE, Klabin I. Por que salvar a Floresta Amazônica. 1st ed. Manaus: Inpa; 1998.

Särndal CE, Swensson B, Wretman J. Model assisted survey sampling. New York: Springer-Verlag; 1992.

Received: August 06, 2013; Accepted: July 28, 2014 